\title{
MICROPROPAGACIÓN DE E. globulus A TRAVÉS DE SEGMENTOS NODALES
}

\author{
PILAR VIDELA S.(*) y PATRICIO CHUNG G.(**) \\ (. *) Bióloga, Instituto Forestal \\ $(* *)$ Ingeniero Forestal(e), Instituto Forestal
}

\section{RESUMEN}

Se determinó el efecto de diferentes concentraciones de $B A P(0,5$ a 2,0 mg $h)$, ANA $(0,01$ mg $h)$ y $A I B(1,0$ a 2,0 $\mathrm{mg} /$ ), en las etapas de multiplicación de brotes, elongación y enraizamiento, respectivamente.

El medio básico de cultivo para las distintas etapas fue MS (Murashige \& Skoog, 1962). suplementado con hidrolizado de caseina y las correspondientes vitaminas.

Se obtuvo mayor formación de brotes al cultivar los segmentos nodales en el medio MS con BAP 1,0 mg/ y ANA 0,01 mg . La elongación y multiplicación masiva se obtuvo al reducir la concentración de BAP $(0,1 \mathrm{mg} /)$ y manteniendo constante la concentración de ANA $(0,01 \mathrm{mg} /)$.

La formación de raíces fue similar en los tratamientos aplicados, destacándose el cultivo de brotes en medio MS a la mitad de su concentración, suplementado con 2,0 mg $/$ de AIB por cinco dias. En la aclimatación de plantas ex-vitro, el porcentaje de sobrevivencia fue de un $70 \%$.

Palabras Clave: Cultivo de Tejido, Segmento Nodal, Eucalytus globulus.

\section{ABSTRACT}

Different concentrations effect with BAP (0.5 to $2.0 \mathrm{mg} / \mathrm{l})$, ANA $(0.01 \mathrm{mg} /)$ and $\mathrm{AIB}(1.0$ to $2.0 \mathrm{mg} / \mathrm{l})$ in the stages of shoot multiplication, elongation and rooting, were evaluated.

The base culture was MS (Murashige \& Skoog, 1962) for different stages. This was supplemented with hydrolysated casein and its corresponding vitamins.

The best shooting results were obtained in nodal segments with $M S, B A P 1.0 \mathrm{mg} \Omega$ and ANA $0.01 \mathrm{mg} /$. Reducing the BAP concentration $(0.1 \mathrm{mg} /)$ and maintaining the ANA concentration $(0.01 \mathrm{mg} h)$, a massive multiplication and elongation was obtained

The rooting was very similar in the different essays, however, the best shoot culture was obtained with the MS with one half the original concentration, adding $2.0 \mathrm{mg} / \mathrm{AIB}$ per five days. In ex-vitro acclimatization plants, the survival rate was $70 \%$.

Keywords: Tissue Culture, Nodal Segment, Eucalytus globulus 


\section{INTRODUCCIÓN}

En Chile, Eucalyptus globulus Labill (E. globulus) es la segunda especie en importancia después de Pinus radiata cubriendo una superficie de 282.982 ha (INFOR, 1995). El rápido crecimiento y vigor de esta especie en una variedad de ambientes y su gran aporte como materia prima, principalmente para la producción de pulpa, hace necesario la implementación de líneas de investigación que permitan rescatar este material genéticamente superior a través de técnicas de propagación vegetativa. Una de estas técnicas es el cultivo in-vitro, requiriendo inicialmente los protocolos de micropropagación y aplicar estos resultados para obtener individuos con crecimientos superiores a la población natural.

El Instituto Forestal (INFOR), a través del proyecto FONDEF "Mejoramiento Genético del Género Eucalyptus", inició los trabajos de micropropagación para lograr resultados que ofrezcan a futuro una rápida propagación clonal en orden a obtener un rápido mejoramiento genético de esta especie, en especial de individuos genéticamente superiores.

La capacidad morfogenética de segmentos nodales de $\boldsymbol{E}$. globulus ha sido evaluada en estudios realizados en varios países, lográndose una producción de brotes arraigados que han garantizado la preservación y multiplicación de material genéticamente valioso (Salinero, 1983).

La regeneración de plantas a partir de segmentos nodales es una forma de cultivar plantas superiores a largo plazo y organizadamente. La multiplicación de brotes a través de meristemas axilares y apicales de plántulas y de material maduro, es la técnica más usada y exitosa en especies de Eucalyptus (Chalupa, 1987). Los procesos naturales para llegar a desarrollar múltiples brotes, pasan por romper la dormancia de las yemas axilares, cultivando segmentos nodales en medio que contenga concentraciones apropiadas de citoquininas.

Esta técnica ofrece una capacidad de propagación clonal de genotipos uniformes con una tasa de multiplicación alta incrementando las ganancias en el crecimiento y la calidad de las plantaciones.

Las técnicas de micropropagación son actualmente una realidad en varias empresas forestales en el mundo. En ellas es considerado estratégico el mejoramiento de la productividad y calidad del bosque. 


\section{OBJETIVOS}

El presente estudio se realizó usando segmentos nodales de plantas de $\boldsymbol{E}$. globulus de dos años mantenidas en vivero. Este material fue sometido a diversos tratamientos con los siguientes objetivos:

- Investigar el efecto de los reguladores de crecimiento BAP (benzilaminopurina), ANA (ácido naftalenacético) y AIB (ácido indolbutírico) en el medio de cultivo para establecer un protocolo de micropropagación de E. globulus.

- Establecer un protocolo de aclimatación de plántulas ex-vitro.

\section{MATERIALES Y MÉTODO}

La investigación es parte del proyecto FONDEF "Mejoramiento Genético del Género Eucalyptus"; y fue desarrollada en el laboratorio de cultivo de tejidos del Instituto Forestal.

Los explantes usados en la etapa de inducción de brotes, corresponde a brotes herbáceos de donde se tomaron los segmentos nodales de plantas de dos años de edad producidas en el vivero de INFOR.

\section{Explantes y Condiciones de Cultivo}

Al ingresar al laboratorio, el material vegetal se lavó con abundante agua para eliminar el polvo, para luego aplicar una mezcla de fungicidas (Captan y Benlate). Posteriormente, bajo la cámara de flujo laminar se sumergieron en una solución de hipoclorito de sodio por 10 minutos, seguido de enjuagues en agua destilada estéril. Adicional a este proceso de desinfección, se aplicó una solución antioxidante compuesta por ácido ascórbico y ácido cítrico. Una vez finalizado el proceso de desinfección, los explantes fueron cultivados en forma de segmentos nodales de $1 \mathrm{~cm}$ de longitud con una porción de hoja de $0,5 \mathrm{~cm}$.

Las condiciones de cultivo para cada etapa fueron las siguientes: fotoperíodo de 16 horas luz a $25^{\circ} \mathrm{C}+/-2^{\circ} \mathrm{C}$ y 8 horas de oscuridad a $18+/-2^{\circ} \mathrm{C}$, la intensidad lumínica dentro de la sala de cultivo fue de 5.000 lux proveniente de lámparas fluorescentes.

\section{Medio de Cultivo}

Para todos los experimentos se usó el medio básico MS (Murashige \& Skoog, 1962). Como fuente de carbono se utilizó sacarosa $20 \mathrm{~g} / \mathrm{l}$ y como gelificante agar $7 \mathrm{~g} /$. El pH se ajustó a 5,7 previo a la esterilización, en autoclave a 1 atm (atmósfera) durante 20 minutos. 
Experimento 1. Inducción de Brotes Múltiples con Distintas Concentraciones de BAP y ANA.

Se usaron segmentos nodales traídos de vivero, los que fueron desinfectados y luego cultivados en tres concentraciones de la citoquinina BAP: 2,0, 1,0 y $0,5 \mathrm{mg} / 1$ suplementado con la auxina ANA $0,01 \mathrm{mg} /$. El medio básico (MS) fue suplementado con hidrolizado de caseína ( $150 \mathrm{mg} / \mathrm{l}$ ). Se colocó un explante en cada frasco con $10 \mathrm{ml}$ de medio de cultivo. Cada tratamiento se implementó con 20 explantes.

Después de 21 días de cultivo se evaluó el establecimiento de los explantes y, además fueron subcultivados a un medio fresco. A los 42 días se evaluó el número de brotes inducidos, contando los brotes axilares y la longitud, medida en centímetros.

Experimento 2. Elongación y Multiplicación de Brotes.

Se usaron los explantes provenientes del ensayo anterior. Este experimento consistió en disminuir las concentraciones de $\operatorname{BAP}(0,2,0,1$ y $0,05 \mathrm{mg} / \mathrm{l})$ y mantener la de ANA $(0,01 \mathrm{mg} / \mathrm{l})$. El medio de cultivo se mantuvo, pero se eliminó la caseína hidrolizada. Las condiciones de cultivo se mantuvieron y el número de frascos por tratamiento fue 20 . A los 21 y 42 días se realizó un subcultivo a medio fresco y el día 63 se evaluó la altura y el número de brotes multiplicados.

Experimento 3. Inducción Radicular.

La inducción radicular se realizó aplicando la auxina ácido indol butírico (AIB) en distintas concentraciones, bajo intensidades de luz diferentes y con distintos tiempos de permanencia en la auxina (Loach, 1985). Se cultivaron brotes de $2 \mathrm{~cm}$, provenientes de los experimentos anteriores, en tres tratamientos:

A) Se sumergieron los explantes en una solución de AIB $1 \mathrm{mg} / 1$ durante 1 minuto, luego se cultivaron en medio base MS diluida a la mitad de su concentración.

B) Se cultivaron los explantes en medio MS diluida a la mitad de su concentración, suplementado con $2 \mathrm{mg} / \mathrm{l}$ de AIB. Se mantuvieron en este tratamiento durante 5 días en la oscuridad, para luego trasladarlos a medio fresco sin hormonas con fotoperíodo de 16 horas luz.

C) Los explantes se cultivaron en medio MS diluido a la mitad de su concentración suplementado con $1 \mathrm{mg} / 1$ de AIB, durante 30 días, bajo condiciones de cultivo con 16 horas luz a $25^{\circ} \mathrm{C}$ y $18^{\circ} \mathrm{C}$ en horas de oscuridad.

Cada tratamiento constó de 20 brotes, siendo evaluados a los 30 días desde su inicio, obteniendo el porcentaje de explantes enraizados en cada tratamiento 
Experimento 4. Aclimatación ex-vitro de Explantes Enraizados in-vitro.

Se trasladaron 30 plántulas enraizadas in vitro de $6,0 \mathrm{~cm}$ de altura (Figura 1), a bandejas que contenían como sustrato turba y arena en una proporción de 1:1 v/v previamente esterilizado en autoclave. Una vez realizado el trasplante se regó con abundante agua destilada estéril, hasta humedecer el sustrato y se cubrió la bandeja con un plástico fino y transparente. Las condiciones ambientales en que se mantuvieron las plántulas corresponden a las de la sala de cultivo. A partir del día 2, la bandeja se mantuvo descubierta por 5 minutos, en forma progresiva se aumentó el tiempo de exposición a las condiciones ambientales, 3 minutos cada día, hasta el día 25 cuando se descubrió por completo la bandeja que contenía las plántulas. A los 30 días las plántulas sobrevivientes se trasladaron a tubetes que contenían sustrato orgánico compuesto por corteza de pino y tierra de hoja en una proporción de 1:1 v/v. La evaluación de los resultados se midió a los 30 días desde el inicio del ensayo

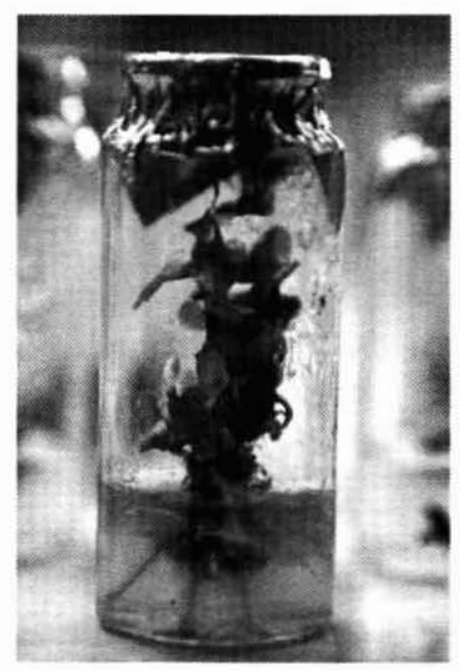

Figura 1. PLANTA DE E. globulus ENRAIZADA in-vitro Y ACLIMATADA ex-vitro.

\section{RESULTADOS}

\section{Experimento $\mathbf{N}^{\circ} 1$}

El Cuadro 1 muestra la respuesta de los explantes a los 21 días medido en términos de infección y explantes muertos; además el número de brotes contabilizados a los 42 días desde el inicio del ensayo y la longitud de los mismos, (Figura 2). 
El porcentaje de infección fue bajo, entre 1-2\%, no registrándose mortalidad en los 3 tratamientos. Sin embargo, el tratamiento 2 presentó la mayor cantidad de brotes inducidos y los más elongados. El Tratamiento 1 indujo brotes pequeños y escasos y en el tratamiento 3 la formación de brotes fue superior al tratamiento 1 pero inferior a la del tratamiento 2 .

\section{Cuadro 1}

RESPUESTA DE SEGMENTOS NODALES DE E globulus A TRES TRATAMIENTOS CON DISTINTAS CONCENTRACIONES DE BAP EN LA ETAPA DE ESTABLECIMIENTO.

\begin{tabular}{|c|c|c|c|c|c|c|c|}
\hline $\begin{array}{c}\text { Tratamient } \\
0\end{array}$ & BAP & ANA & $\begin{array}{c}\mathbf{N}^{\circ} \\
\text { explante }\end{array}$ & $\begin{array}{c}\text { Porcentaje } \\
\text { Infección } \\
(\%)\end{array}$ & $\begin{array}{c}\text { Porcentaje } \\
\text { explantes muertos } \\
(\%)\end{array}$ & $\begin{array}{c}\mathbf{N}^{\circ} \text { de brotes } \\
\mathbf{X}(\mathbf{m} / \mathbf{4})\end{array}$ & $\begin{array}{c}\text { Longitud } \\
\text { brotes X }(42 \\
\text { días }) \\
(\mathrm{cm})\end{array}$ \\
\hline 1 & 2,0 & 0,01 & 20 & 1,0 & 0,0 & 3 & 0,2 \\
\hline 2 & 1,0 & 0,01 & 20 & 0,0 & 0,0 & 10 & 0,5 \\
\hline 3 & 0,5 & 0,01 & 20 & 2,0 & 0,0 & 6 & 0,3 \\
\hline
\end{tabular}
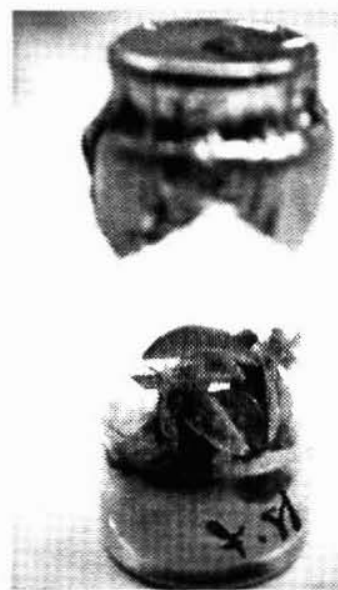

Figura 2. EXPLANTES EN ETAPA DE ESTABLECIMIENTO Y BAJO EL EFECTO DE TRES CONCENTRACIONES DE BAP

\section{Experimento $\mathrm{N}^{\circ} 2$}

En el Cuadro 2 el número de brotes obtenidos se destacó en el tratamiento 2 al igual que la elongación de los mismos. Aunque al comienzo no se observaron diferencias al momento de contabilizar y medir los brotes se determinó la diferencia existente entre los tratamientos, (Figura 3) 


\section{Cuadro 2}

PROLIFERACIÓN Y ELONGACIÓN DE BROTES, FRENTE A TRES CONCENTRACIONES DE BAP.

\begin{tabular}{|c|c|c|c|c|c|}
\hline Tratamiento & $\begin{array}{c}\text { BAP } \\
(\mathrm{mg} / \mathrm{l})\end{array}$ & $\begin{array}{c}\text { ANA } \\
(\mathrm{mg} / \mathrm{l})\end{array}$ & $\mathrm{N}^{\circ}$ explante & $\begin{array}{c}\mathbf{N}^{\circ} \text { de brotes X } \\
\text { (42 días) }\end{array}$ & $\begin{array}{c}\text { Longitud brotes } \mathrm{X} \\
(\mathbf{4 2} \text { días }) \\
(\mathrm{cm})\end{array}$ \\
\hline 1 & 0,2 & 0,01 & 20 & 7 & 0,8 \\
\hline 2 & 0,1 & 0,01 & 20 & 16 & 1,6 \\
\hline 3 & 0,05 & 0,01 & 20 & 9 & 1,0 \\
\hline
\end{tabular}

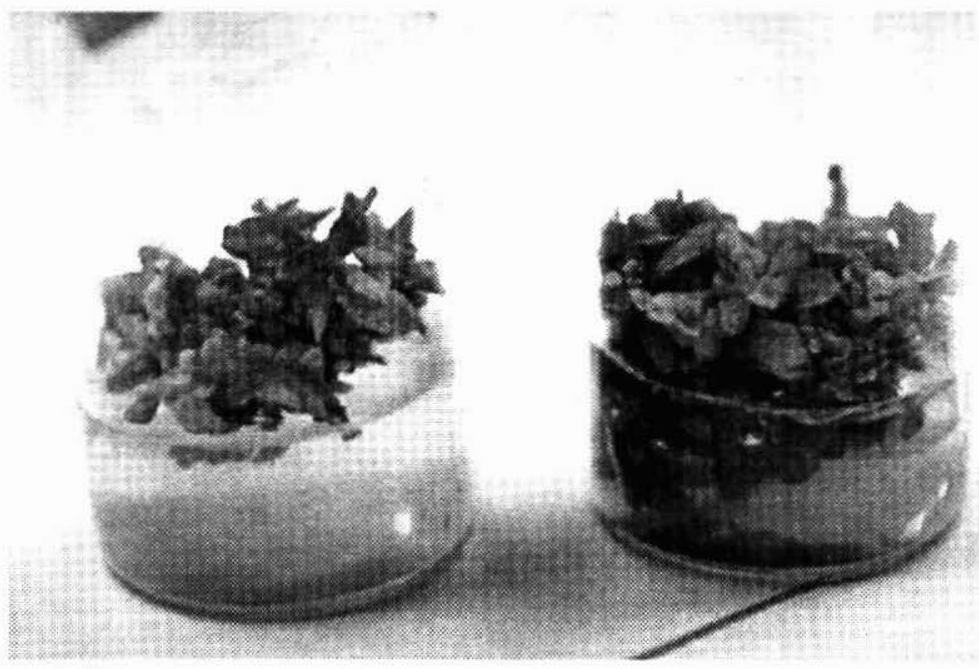

Figura 3. EXPLANTE DE E. globulus EN ETAPA DE MULTIPLICACIÓN

\section{Experimento $\mathrm{N}^{\circ} \mathbf{3}$}

El Cuadro 3 muestra la respuesta de los explantes en los tres tratamientos, logrando resultados exitosos que superaron el $80 \%$ de brotes enraizados (Figura 4). La diferencia está en la masa radicular que se formó en cada tratamiento y la rapidez con que empezaron a responder. En el tratamiento $\mathrm{A}$, las raíces emergieron una semana más tarde que en B y C, sin embargo no hubo formación de callo en la base de los explantes. En el tratamiento B hubo una pequeña formación de callo en el 5\% de los explantes y las raíces emergieron más temprano que en los otros tratamientos. En el tratamiento $\mathrm{C}$ la formación de callo ascendió a un $20 \%$ y las raíces presentaron un aspecto más fino que las obtenidas en los tratamientos A y B. 


\section{Cuadro 3}

\section{RESPUESTA RADICULAR DE BROTES CULTIVADOS in vitro FRENTE A TRES TRATAMIENTOS.}

\begin{tabular}{|c|c|c|c|}
\hline Tratamiento & $\begin{array}{c}\mathrm{N}^{\circ} \\
\text { explante }\end{array}$ & $\begin{array}{c}\text { Porcentaje explante } \\
\text { con callo } \\
(\%)\end{array}$ & $\begin{array}{c}\text { Porcentaje explantes } \\
\text { enraizado } \\
(\%)\end{array}$ \\
\hline A & 20 & 0,0 & 80,0 \\
\hline B & 20 & 5,0 & 95,0 \\
\hline C & 20 & 20,0 & 85,0 \\
\hline
\end{tabular}

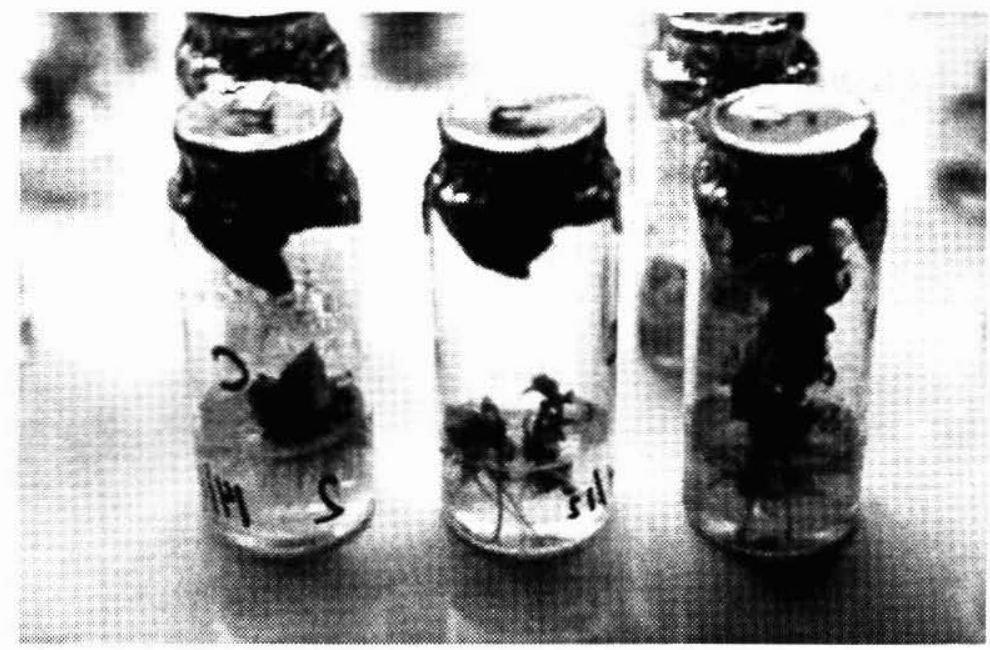

Figura 4. EXPLANTE DE E. globulus ENRAIZADO in vitro.

\section{Experimento $N^{\circ} 4$}

Los resultados de este ensayo fueron medidos en porcentaje de sobrevivencia a los 30 días de iniciado el ensayo, lográndose un $70 \%$ de plántulas vivas al momento de salir del laboratorio a vivero. Esta etapa deberá seguir siendo ensayada para evaluar el comportamiento de las plantas en vivero, investigación aun pendiente.

\section{DISCUSIÓN Y CONCLUSIONES}

El porcentaje de brotes obtenidos en la etapa de establecimiento varió con el tratamiento lo que indica que la concentración de BAP incide directamente en la formación de brotes en los explantes usados en iguales condiciones de cultivo. Existe una relación en la altura de los brotes en los tres tratamientos y en la cantidad de brotes formados, destacándose el mismo tratamiento (BAP 1,0 mg/l + ANA 0,01 mg/l). 
En la etapa de multiplicación de brotes se vuelve a presentar una clara diferencia en la respuesta de los explantes frente a los tratamientos aplicados, destacándose el tratamiento de BAP $0,1 \mathrm{mg} / \mathrm{l}+$ ANA $0,01 \mathrm{mg} /$, tanto en el incremento de brotes obtenidos como en la altura de los mismos. Esto indica que la acción de la citoquinina BAP aplicada en estos tratamientos influye directamente en la respuesta obtenida.

El porcentaje de enraizamiento fue similar en los tratamientos aplicados, sin embargo el crecimiento radicular en $\boldsymbol{E}$. globulus varía con el tratamiento usado. Esto indica que aquellos explantes que permanecieron menos tiempo en contacto con la auxina AIB enraizaron sin formar callo en el $95 \%$ de sus explantes. Es posible, además, que la permanencia en la oscuridad durante la etapa de inducción radicular tenga un efecto sinérgico con la concentración de auxina aplicada.

La aclimatación se vió fuertemente influenciada por la humedad y la temperatura mantenida tanto mientras las plántulas estaban cubiertas y sometidas a condiciones ambientales. Lo que marcó el éxito de esta etapa fue el ejercicio de aclimatar paulatinamente las plántulas permitiendo que los procesos fisiológicos de las plántulas se fueran normalizando, hasta lograr su sobrevivencia en condiciones ambientales.

Por lo tanto los resultados obtenidos, permiten continuar investigando para llegar a optimizar los resultados, pudiéndose montar una línea de multiplicación a nivel operacional.

\section{BIBLIOGRAFÍA}

Chalupa V. 1987. European hardwoods. In : Bonga JM, Durzan DJ (Eds) Cell and Tissue Culture in Forestry, Vol. 3 (pp. 224-246)

INFOR. 1995. El Sector Forestal Chileno. Documento de divulgación.

Leakey, R.R.B. 1985. The capacity for vegetative propagation in trees . In attributes of trees as Crop. Plants. (M.G. Cannell and J.E. Jackson. Editors). Institute of Terrestial Ecology. Abbotts Ripton, England. pp 592.

Loach, K. 1985. Rooting of cuttings in relation to the propagation medium. Proc. Inter. Plant. Prop. Soc. 35. pp 472-485.

Murashige,T. Skoog, F. 1962. A revised medium for rapid growth and biossays with tobacco tissue cultures. Physiol. Plant. pp 473-497.

Salinero, M.C. 1983. Advances in micropropagation of Eucalyptus globulus by in vitro nodal culture. In Colloque International sur les Eucalyptus resistants au froid Bordeaux, France. Pp:609618 . 